\title{
Challenges of the English Teacher in the Engineering Faculty
}

\author{
Ramirez Valencia Astrid ${ }^{1}$, Borja-Alarcón Isabel ${ }^{1} \&$ López-Vega Alfonso $^{1}$ \\ ${ }^{1}$ Faculty of Science and Education, Universidad Distrital Francisco José de Caldas, Bogotá, Colombia \\ Correspondence: Ramirez Valencia Astrid, Faculty of Science and Education, Universidad Distrital Francisco \\ José de Caldas, Bogotá, Colombia. E-mail: astramirez@gmail.com
}

\author{
Received: December 6, 2017 Accepted: January 20, 2018 Online Published: January 23, 2018 \\ doi: 10.5539/elt.v11n2p149 URL: http://doi.org/10.5539/elt.v11n2p149
}

\begin{abstract}
Changes experienced in recent times focus their attention on new and multiple challenges that must be assumed by the English teacher, in the engineering context, which becomes a challenge against the demands by the current world from the English teacher in Colombia.

This situation needs to be analyzed and studied. This article addresses the challenges of teaching English in the engineering context in Colombia, in order to glimpse actions in terms of perspectives, reflecting on how these aspects promote this new teacher, in the new century in which we are living.
\end{abstract}

Keywords: challenge, engineering, English teaching, innovation

\section{Introduction}

Firstly, it should be recognized that the activity carried out by the engineering English teacher in Colombia is changing and dynamic, demanding major challenges. Therefore, this teacher should be able to perform adequately, in the context offered by the University, institution which demands him/her to have the knowledge for being able to face all the situations presented in this century; for this reason, it is important that this teacher acquires the appropriate tools to teach the new skills demanded by this challenging Colombian society.

This new teacher, in the engineering context, must have the ability to investigate the reality, intervening it, by proposing innovations and changes in the institutions that offer this kind of programs. As a consequence, the teacher will have to manage methodological changes which allow the students (future engineers) to acquire higher levels of proficiency in the foreign language.

It is undeniable that the current world requires a foreign language teacher who is able to face the challenges imposed to the current University. Pereda (2010) affirms that factors such as social, technological, general changes and even, political conditions, demand from this teacher, to be a facilitator of knowledge, educating future competent engineers in different areas of expertise and knowledge; in this way, they are contributing to the support of other economical production ways, as a gear in the process of globalization. This has caused that the English professor faces different challenges. This article aims to reflect on the challenges posed by the new globalization conditions to this teacher in Colombia.

\section{Development}

Currently, English teachers face a variety of challenges, which require being proficient with the use of tools that allow them to act effectively and efficiently, in this new century.

For this purpose, it is suggested to take any of these actions. In the first instance, English teachers in the engineering context should be organized, so they need to prepare many activities to be developed in the classroom. Second, they have to build an optimal scenario, whether in person or online, for developing the English classes. Third, they need to provide clear instructions by explaining the activities to be implemented in the classroom. Finally, these teachers have the responsibility to develop, in the students, reflective thinking systematically, so students must be able to think about what happened in the classroom when they are involved in the pedagogical activity, as well as the way they face the reality presented in the University context, where they are trained to be engineers.

\section{The New Challenges}

It is expected that these actions will lead English teachers in engineering programs, to self-learning proposals, 
urging them to acquire the commitment to continue with their education, so that it becomes a life project. Many of the characteristics that determine this faculty are framed in their roles and in their educational work, so it is suggested that, in the first instance, teachers have to plan activities that foster independence and success in the students, by enabling the development of skills and feelings of welfare, with respect to themselves and the others, in relation to the situations that are affected by the environment in which events happen.

That purpose will be always achieved when the students have a good proficiency level in a foreign language. This leads to say that it is important that teachers give clear instructions, being sure that the student understands exactly what to do.

Sometimes, it is common to recognize that this situation often leads to misunderstandings, especially when the professor teaches a foreign language because the instructions are usually given in a different language from the mother tongue, with the risk of not understanding what learners must do in the classroom.

At the same time, it is important that the engineering students identify the relationship between the new and old knowledge, by making a relationship with the reality.

To achieve this goal, it is suggested that teachers select the materials that will be used in class appropriately. Consequently, they should consider, at first, the age of the pupils; second, the total number of students, and finally, their needs and expectations.

For this reason, it is necessary to consider the apprentices' perception and experience, related with the materials used in the English class, allowing to articulate this knowledge within their professional future; by establishing different relationships between language, knowledge, and engineering.

Besides, the English teacher needs to promote creativity and imagination on the students, by allowing them to dream and enter into the environment offered by the world of learning a foreign language; these situations probably make them be aware of many ways of learning a language, by exploring the multiple scenarios presented through this experience. At the same time, it is necessary to consider that the materials addressed in the course must be authentic; thus, the English language student from an engineering program will have a real contact with the English language culture.

Finally, the time for the development of each session plays an important role in this situation. In many cases, the time devoted to fulfilling a L2 curriculum is few, going around 50 hours per semester. And additionally, the whole English course is composed of five levels.

\section{Use of Authentic Materials}

All these arguments are contemplated by Tomlinson (2011), who claims that English students at the Engineering Faculty should be exposed to authentic materials, with the objective of making them be familiar with a real input. It forces them to be familiar with a real and meaningful input.

In addition, they will be more focused on building meanings than studying forms, and more oriented to understanding than in early production.

So, it is expected that the English engineering students internalize the language before producing; for this reason, the teaching process must be involved in communication tasks that promote interaction. It also demands that English teachers discuss the learning styles of the future engineers by including various activities; Finally, it is suggested to consider the learners' emotions when they are developing all the language activities in the English classes.

Similarly, teachers need to make use of the resources found in the network. These tools not only provide motivation and a true learning environment, but they also contribute the future engineer; the chance to achieve a good mastery of the English language; leading to the use of the English language in a natural and authentic way, by giving the opportunity to develop critical thinking about the contact with other cultures, for example.

It creates a need of spaces where would be possible to express their opinions and feelings regarding the use of this type of aids, demonstrating the effectiveness of these instruments by potentiating the domain of the English language.

As a result, multimedia materials have a high impact by owning a significant and valuable potential, by their authenticity, offering new learning ways which respond to the students' needs, especially, because they are in a constant process of update and transformation. For this reason, both the teacher and the student can obtain renewing and changing information on a permanent basis.

Thus, multimedia materials respond to the method, to the teaching and learning strategies, styles and many other 
aspects related to teaching a foreign language in an engineering context. Considering the ideas previously and, from a humanistic point of view, when students are exposed to materials that they consider as interesting and useful, their interest in knowledge is promoted and stimulated; at the same time, it is possible to do a greater mastery in people who are learning a language.

Meanwhile, multimedia promotes communicative, interactive and widely enriching opportunities for multiple perspectives that will strengthen the commitment that implies in learning a foreign language, in this case, English. Therefore, we must emphasize that the teacher has the responsibility to choose rigorously, the most suitable materials for the future engineers, taking into account their learning needs, different contexts, ages, and many of the other variables previously mentioned.

\section{The English Teacher as a Mediator in the Engineering Context}

Another element which is inherent to the pedagogical work of the English teacher in the engineering context is being a mediator. Unlike traditional teachers, sometimes conceived as the unique source of knowledge, the current situation is completely different; for this reason, those teachers were asked to take inflexible and widely standardized positions. Currently, this situation is changing, and consequently, teachers are required to guide the learners, in the way they have access to the knowledge, in a simple and easy way, promoting self - esteem, self learning and collaborative work in the apprentice.

Regarding this, Tébar (2005) considers that the teacher, as a mediator, has the primary responsibility of enhancing student's skills; for this reason, he explains, his/her role as transmitter is to minimize and emphasize the use of abilities and skills, oriented to provide ideas and advice to the students.

This author also talks about the role of facilitator, conceiving it as a teacher who uses tools and strategies that the future engineer can access to the knowledge in the L2.

In other words, as Wayne (2003) explains, the teacher as a mediator, must design tasks and provides assistance to the students through teaching materials that allow them to understand the English language, by clarifying and presenting concepts and knowledge related with this discipline.

This indicates how the English teacher can be a mediator between the knowledge and the real world, which means that the teacher will build a bridge between knowledge, the universe in which students are involved, causing that the students achieve the foreign language appropriately, a requirement established by the Common European Framework of Reference.

In addition, to face the demands of the $21^{\text {st }}$ century, the English teacher must become an apprentice while he/she is developing the profession. Traditionally, the society conceived that the student is the only one who learns. However, in this modern world, there is a tendency to reevaluate this concept, considering that the teacher also learns from all the events that are happening in the contexts, and mostly, at the moment that he/she develops his/her pedagogical role.

Based on this, the English teacher needs to be in a constant learning process, especially when he/she is in contact with the students, due to the easy access to cyber media. In many cases, it is common to find that the students can help the teacher with the use of some technological materials, because they have the experience and are more familiar with those instruments, which are commonly present in the classroom, and sometimes, the teacher is not able to control them.

As a result, the current and future English teacher cannot go on his/her teaching pace, on the contrary, he/she must be adapted to the pace of his/her students. It means teachers must consider the individual learning style of their students, in order to develop their work, according to their needs and demands. As indicated by Mayor (2000), teachers must go from the teaching perspective to the learning perspective; from unidirectional to multidirectional or diverse studies, making possible multiple movements through appropriate ways, intermediate accreditations, and others. In other words, it is necessary to go from a temporal training (a normal term for an academic program) to permanent training (advanced specialization courses, intensive and updating training, and others).

This indicates that the teacher must be conscious that his / her learning must be constant, permanent and must not stop because this process never finishes if he/she pretends to be attentive to the academic advances which happen in the global context. This leads us to think about the need to be conscious about our daily work as English teachers because by making suggestions, bringing up new ideas and, sometimes, rethinking about what to do in class, we are learning.

Therefore, it is necessary to recognize that English professors are in a process of lifelong learning, taking as their starting points, the students' attitudes in class; their answers, signals, ideas, and all the other input that can be 
detected by the teachers.

\section{The English Teacher as a Critical and Researcher in the Engineering Context}

It is possible to affirm that the English teacher is conceived as an apprentice involved in a critical and reflective process of his / her teaching, committed with a constant questioning and inquiry that leads him/her to wonder about the events in the classroom, the reaction of his students, the organization and management of the class, worrying about the historical, cultural, social and political events that takes place around the world, in order to take them as sources of research.

In this line, Perez (2010) suggests that the reflective teacher can diagnose the different states and movements of the complex life in the classroom, from the perspective of those involved in it, developing, experimenting, evaluating and redefining modes of intervention, based on the educational principles that justify and validate the practice and the individual and collective evolution in the students, clearly defining it as a research process in the real context.

With this perspective, it is important to determine the connection between reflection and research, due to the permanent links and suggested meetings in the educational scenario, resulting it in an important relationship which allows to detect, analyze and propose solutions for the real situations presented in the classroom, based on practical and theoretical foundations.

Therefore, we can consider that the challenges imposed to the English teacher in the $21^{\text {st }}$ century, demand him/her to be a researcher. Currently, there is a tendency to consider that research is only devoted to important experts who suggest the teachers, the actions to carry out.

However, reality shows us that researching is linked with the teachers' work, especially because they are constantly reviewing and checking their actions inside and outside the classroom; and at the same time, they are frequently thinking about what is happening; watching each situation that occurs in the school community, because the purpose is to decide what is useful, and reformulate what was not useful. In this sense, the English educator is in a constant exercise of inquiry, in face of the activities within or outside the classroom, facing all the events in the context where he/she works, or any other scenario where he/she is involved; for this reason, it is indisputable that the teacher is a researcher, not a passive recipient of theories.

Similarly, Stern (1991) argues that, in the engineering context, intuitions from the teacher and the future engineer, with their experiences, can contribute with ideas, information, problems, and questions, to the development of the theory of language pedagogy and the basic disciplines. That means, the pedagogical exercise, developed in the classroom, is mediated with the interaction between teacher and student, allowing to enrich the ideas related to the language learning field, by the teacher.

Additionally, Richards (2014) adds that the teacher is a researcher in the classroom; subsequently, he has the responsibility of determining what aspects he/she wants to know or learn more or better. In other words, questioning about their teaching and educational performance, determining the possible difficulties and methodological deficiencies presented to the future engineers in the University, in order to find appropriate ways to solve them. Furthermore, the teachers will be developing, almost unconscious research; a process which will generate high - impact results in the engineering faculties.

This exercise should be accompanied by the systematization of the experiences, as well as a permanent reflection and inquiry on the findings, failures and successes, in order to get that this knowledge remains accessible to all people, to transform the English teaching processes, causing that research becomes a useful tool for the university in general, and for the engineering faculties in particular, evidencing research from the action by the English teacher, and validated by the achievement of the learners' high proficiency levels in English.

\section{Discussion and Interpretation}

In addition, the English teacher, in the 21st century, must make interactions, because of facing a new University, in order to stop being a transmitter of information, leading him/her create a class environment where reciprocal interaction, dialogue, and clash of knowledge, by both the student and the teacher, become a priority. This, aiming that everyone feels involved in an experience which will allow them to understand and use the foreign language in real and practical situations for the future engineer.

Martinez (2007) explains that the teaching process, in general, has been single - centered, and this has to be changed, making it multi-centered, aimed to satisfy the students' learning interests. By this way, the English teacher is not the unique source of knowledge at hand; as contrary, he/she is involved in the movement of information offered by the network, which allows him/her to access the knowledge. Consequently, the teacher should involve the students' topics of interest, realities, problems, and difficulties, in his / her classes, as well as the 
situations presented in the local, national and global context.

English teachers need to promote an interaction, based on the communication between students, colleagues, directives, and other agents from the university, creating a dynamic and comprehensive climate among the members, that contributes to promote a nice relationship between students and students, students and teacher, learners and directives and teacher and directives, in order to foster a favorable environment for learning a foreign language, within which individuals can interact without a hierarchy discrimination, creating a democratic participation context between the members of a community.

In regards to that, Schumann (1978) states that the Advisor cannot adopt an attitude of indifference for the students; on the contrary, it requires a special attention in which educational institutions must bring an acceptability atmosphere, in the classroom. Consequently, he/she must provide many opportunities for promoting an open, free and collaborative communication between students and English teachers.

To achieve this goal, the educator must create a climate of understanding in the classroom, characterized by a friendly and positive treatment for the students in there. Thus, the relationships created in academic spaces will be raised in an atmosphere of kindness and familiarity among all members of the academic community.

Morell (2004) also clarifies that, if the English teacher decides to be an expert in his/her field of knowledge, he/she would consider that it would be strictly limited to the theoretical content in the hours spent on the course, without considering the rest of elements that can happen inside the class.

Similarly, if the contact between students and teachers is limited only to the class hours and, if a relaxed environment is not created, the student is probably going to take a passive role and the learning process will be less effective, mainly, for the students.

On the contrary, part of the power could be given to the students through the use of language, both verbal and nonverbal. As a consequence, they will take a more active role inside the classroom, increasing the emotional involvement which can create a more receptive and positive environment for the language learning process. This type of attitudes reverses their effects in the promotion of a more effective and permanent learning, especially, for the learners who, when feeling relaxed and motivated for acquiring knowledge through teaching this foreign language, they could be more competent in its domain.

Another aspect of importance in the present century is the need of being an English teacher with a sense of justice. Therefore, this teacher must take into account the principle of democracy and participation of all members who are part of the classroom. For this reason, he/she must always keep in mind the importance of promoting a permanent dialogue with the directives and administrative staff, in order to create a close encounter of points of view that facilitate decision-making processes by the directives.

In connection with this perspective, Escudero (2006) explains that the teacher will always act democratically rather than authoritatively, offering equal opportunities to all the members, and also suggest actions naturally, without assuming attitudes of superiority and omnipotence in front of his/her students.

It is evident the existence of another way of learning, based on tolerance, democracy, and acceptance of the others and their differences. At the same time, this will probably lead to the communication, the dialogue, the participation and the collective construction of knowledge of the English language, under democratic conditions.

It is necessary to include the need to be a flexible English teacher, in front of the presence of many situations where the teacher control is not evident, therefore, it is impossible to take action with total stiffness during the development of the class; instead, it is recommended to promote a permanent dialogue.

Consequently, this teacher will intervene in the school context, demonstrating adaptability, awareness and constant concern, to understand that all educational scenarios have many particular characteristics to be considered, therefore, teachers need to organize their classes, considering that each environment is different from the other, especially in the case of teaching a foreign language.

As Brooks and Brooks (2010) clarified, the English teacher will be flexible in organizing the class, allowing the student's interest and responses guide in the course sessions for determining teaching strategies that sometimes, can modify the content. Within this framework, it is important the autonomy, the critical thinking, the teamwork and the leadership, as relevant characteristics that should be inherent to this teacher.

Teachers also need to be servers. It means that, in addition to the transmission of values, techniques and general or specific knowledge, teachers should facilitate the pupil's learning process through the access to the web, where they can find exercises and resources which allow them to be involved in their own process, causing that they achieve a higher level of proficiency in a foreign language. 
At the same time, the educator must familiarize the future engineers with learning situations where they have the opportunity to access to the knowledge, considering their needs, age, social and cultural context, among other factors. For this reason, the English teacher will take into account all these variables when designing materials, explaining the topics to the student, developing activities, as well as evaluating content and performance, among other actions.

Even, it is urgent to reflect on how technological media have made the world a global village, a fact that in the future, could affect the culture of a country; here, it would be pertinent to think about what to do about it.

In this regard, we must emphasize that a foreign language teacher, in this faculty, in Colombia is called to be an advocate of cultural identity. To reach this purpose, it is appropriate to review the concept of cultural identity which, according to Cardoza and Aragón (2016), is defined as the set of values, traditions, symbols, beliefs and behaviors that operate as a cohesive element within a social group, and act as a support for individuals who want to construct their sense of belonging. Consistent with this view, cultural identity is of great importance in the University; Estupiñan and Agudelo (2009) suggest that the University is a place where different cultural perspectives are combined and knitted in the academic, social and political lives.

\section{Conclusions}

English teachers at the Engineering Faculty, in the 21st century, are established as apprentices who live in a time and a sociocultural space, with a permanent and changing configuration, which would demand them a high commitment to continue preparing and updating their knowledge.

Similarly, it demands a lifestyle choice, humanly oriented for building a fairer, cooperative and equitable society, with actions that let achieving peace, respect for life and diversity, being reflected in all the educational processes occurring in the University, which are expected to be based on communication and interaction between all the members of the academic community.

At the same way, the English teacher needs to be involved in a commitment of innovation, as a construction of scenarios of permanent pedagogical learning that supplies the needs and demands of the global context, permitting to create knowledge, based on a permanent reflection, creativity, and research.

Today's world also requires that the English teacher must be able to be in charge of other challenges for facing the various situations presented in the University.

From this point of view, the teacher needs to state different ways of thinking that go beyond the traditional ideas, in order to satisfy the needs of this global world.

Then, it is urgent to propose serious changes that enable a renewal of the teaching style of a foreign language teacher, aiming to promote innovations in the field, by implementing new methodologies that are mainly based on media tools.

With this type of alternatives, it will be possible to have an innovative glance that leads this teacher thinking about everyday matters occurring around, and within the classroom environment, responding to the technological advances, social situations occurred in the context in which the school is involved and committed.

Thus, by promoting a different learning environment from the current one, which develops intellectual abilities, accompanied by analytical and critical thinking, it will be possible to allow that students develop their own judgments with which will be able to reason, to confront and balance different views, regarding social axes from their local environment, in contrast with the global perspectives, in which school is involved.

This will probably bring a change in the English teachers, conducting them appropriate their training process, by the way, that the students do not become recipients of information, but on the contrary, teachers must become facilitators of learning by being agents of change, to promote other ways of teaching the English language, in the engineering context, that leads them to become transformational leaders, based on the creation of new ways of teaching, that rescue the local situations without ignoring the global ones, especially in the fields related to culture and our values, in order to become leading researchers, based on the reality, the university and its environment.

To achieve this purpose, it is appropriated to develop a critical thinking that leads the educator to have clear positions about the development of our society, in order to have a future engineer that is able to discern topics generated from the proposals, result of his/her reflections and research.

Similarly, English professors must know the academic, methodological and attitudinal abilities which allow them to make right decisions in unexpected situations at the University, with which they will be able to assume the challenges of the current society, being aware of the changes and demands, due to their status as English teachers in the engineering context in Colombia. 


\section{References}

Acosta, C. (2011). Think Children's Literature. Interpretation of Many Voices. Bogotá: Universidad Nacional de Colombia.

Barners, W., \& Richards, R. (1989). Learning to Teach Modern Languages in the Secondary School. Cambridge: Cambridge University Press.

Brooks, J. G., \& Brooks, M. G. (2010). In Search of Understanding: The Case for Constructivist Classrooms. United States: Association for Supervision and Curriculum Development.

Cardoza, U. (2010). Managua Cultural Identity. Nicaragua: National Engineering University.

Coll, C., Pozo, J. I., Sarabia, B., \& Valls, E. (1994). The Contents of the Reform. Teaching and Learning Concepts, Procedures and Attitudes. Salamanca: Santillana

Escudero, J. M. (2006). Teacher Training and Improving Education. Magazine octahedron, 7, 21- 51.

Estupiñan, N., \& Agudelo, N. (2008). Cultural and Educational Identity Paulo Freire. Journal of Latin American Education History, 10, 25-40.

Martínez, L. M. (2007). The New Role of University Professor of Foreign Languages in the Process of European Convergence and Its Relation to the Interaction, Mentoring and Autonomous Learning. Porta Linguarum.

Martinez, M. J. (1999). The University Teaching of Foreign Languages. Alicante: Publications Service of the University.

Mayor, Z. F. (2000). A New World, Ballantine Books, Galaxy. Gutenberg and UNESCO Publishing.

Morell, T. (2004). The Interaction in the Lecture. Alicante: Publications Service of the University.

Pereda, C. (2010). Good Practices: A Mode of Making Policies from the Centers. Montevideo: CSIC / UDELAR.

Pérez, A. (2010). Learning to Educate. New Challenges for Teacher Training. Interuniversity Magazine of Teacher Training, 8, 72-83.

Richards, J. C., \& Rodgers, T. S. (2014). Approaches and Methods in Language Teaching (3rd edition), Cambridge: Cambridge University Press.

Schumann J. (1978). Social and Psychological Factors in Second Language Acquisition. Rowley, Mass: Jack Richards Newburly House.

Stern, H. H. (1991). Fundamental Concepts of Language Teaching. Oxford: Oxford University Press.

Tébar, L. (2003). The Profile of the Mediator Professor. Madrid: Santillana.

Tomlinson, B. (2011). Introduction. Principles and Procedures of Materials Development. In B. Tomlinson (Ed.)., Materials Development in Language Teaching (2nd edition). Cambridge: Cambridge University Press.

Wayne, A. J., \& Youngs, P. (2003). Teacher and Student Achievement Gains Characteristics: A Review. Review of Educational Research. Cambridge: Cambridge University Press.

Wright, T. (1987). Roles of Teachers and Learners. Oxford: Oxford University Press.

Ynduráin, F. J. (2006). Electrons, Neutrinos and Quarks. Barcelona, Spain: Criticism.

\section{Copyrights}

Copyright for this article is retained by the author(s), with first publication rights granted to the journal.

This is an open-access article distributed under the terms and conditions of the Creative Commons Attribution license (http://creativecommons.org/licenses/by/4.0/). 